\title{
THE RELATIONSHIP OF THROAT INFECTION TO ACUTE RHEUMATISM IN CHILDHOOD*
}

\author{
BY \\ BERNARD SCHLESINGER, M.A., M.D., M.R.C.P. \\ (From the Children's Heart Hospital, West Wickham.)
}

Although two centuries have now passed since the association of angina faucium and rheumatism was first noted, their true relationship still remains in doubt. The uncertainty which shrouds the problem is best reflected in the difference of opinion with regard to tonsillectomy in rheumatic cases, a point on which the medical profession have never been able to agree.

The original plan of removing septic tonsils in an attempt to eradicate or prevent rheumatic infection was based on a logical line of reasoning. But the method soon got out of hand and the operation was recommended by some enthusiasts in every case of rheumatism, regardless of the state of the tonsils and the condition of the patient. Many failures resulted and a reflection was cast on a method which at first was only intended for limited application. Reaction followed and there is now a fairly widespread disbelief in the operation as a potent factor in arresting the rheumatic process.

Notwithstanding this there is still general agreement that rheumatic children are specially subject to chronic tonsillar infection. Those who desire statistical evidence of this have only to turn to the special Medical Research Council Report ${ }^{1}$, or to the writings of Mackie ${ }^{2}$, Lambert ${ }^{3}$, Miller ${ }^{4}$, and St. Lawrence $^{5}$. The percentage incidence of septic tonsils given by the last two authors, although working as far apart as England and America, is almost identical, namely, 83 per cent. and 82 per cent. This is the more remarkable since it is not always easy to exclude a septic tonsil and there is no accepted standard. Large tonsils are not necessarily diseased and it is often a small harmless looking pair with corresponding enlarged glands which harbours infection. Enquiry into a history of sore throats in rheumatic children (Poynton ${ }^{6}, 31$ per cent.; Bertram², 28 per cent.; Miller ${ }^{4}, 33$ per cent.), reveals a much lower incidence than the great frequency of septic tonsils would suggest. This is not surprising considering the evanescent and often painless nature of tonsillitis in childhood.

Figures dealing with previous attacks of tonsillitis, which in many cases must necessarily have been compiled from the patients' histories, can only be approximate. The subjective symptoms of sore throat may be absent or so slight that statistics collected by enquiry are bound to be fallacious. Often the attack of tonsillitis is only manifested by a sharp rise of temperature with general malaise, which is either regarded as a common cold, or may pass

\footnotetext{
* From a thesis accepted for the M.D. (Cantab.).
} 
unnoticed unless the child is under close medical observation. These minor throat infections may also be missed in rheumatic clinics or hespital cutpatient departments, and the true course of rheumatism in childhood can only be properly appreciated by a daily record of the patient's temperature and pulse rate, and frequent clinical examinations extending over a considerable period. This is only possible on a large scale at a special heart hospital, where the children reside for many months after their acute rheumatic attack until they are fit to return home.

The present investigation is based on four years clinical study of this particular problem at such a hospital for children with rheumatic heart disease. Its purpose is to bring forward some fresh evidence of the direct relationship between thrcat infection and rheumatic relapses. An explanation of the sequence of events will be attempted, and from it deductions as to the best methods of prophylactic treatment will be made.

Rheumatic relapses following naso-pharyngeal infection.-Epidemics of pharyngeal infection occurred in 1927, 1928 and 1929 at the West Wickham Hospital for children with rheumatic heart disease. On each occasion the epidemic began in the winter, lasted several months and then gradually subsided in the spring or summer. It could not be shown from throat cultures taken during the tonsillitis that any particular type of streptococcus

TABLE 1

The influence of tonsillectomy in ePidemics of thrót infeCtion.

\begin{tabular}{l|c|c|cc|c}
\hline & $\begin{array}{c}\text { Total } \\
\text { number } \\
\text { examined }\end{array}$ & $\begin{array}{c}\text { Acute naso- } \\
\text { pharyngeal } \\
\text { infection in }\end{array}$ & $\begin{array}{c}\text { Relapse of } \\
\text { rheumatism } \\
\text { in }\end{array}$ & $\begin{array}{c}\text { No relapse of } \\
\text { rheumatism } \\
\text { in }\end{array}$ \\
\hline Tonsillectonized children & 224 & $16 \quad(7 \%)$ & $8 \quad(3$ mild $)$ & 8 \\
\hline Non-tonsillectomized & 261 & $46 \quad(17 \%)$ & $14 \quad(3$ mild $)$ & 32 \\
\hline
\end{tabular}

was responsible for the infection. In most cases the tonsillar infection was not severe and, since a complaint of sore throat even at the height of the attack was uncommon, the lesion might easily have passed undiscovered had not a search for the cause of the sudden pyrexia been made.

No sequelæ followed the tonsillitis in the majority of patients, (40 out of 62 , see Table 1), and after a sharp pyrexio and increased pulse rate the faucial inflammation subsided, the temperature dropped to normal, and in two or three days complete recovery occurred. In a certain number, (22 out of 62) after an approximate interval of 10 to 21 days the temperature rose again and was accompanied by a relapse of rheumatism. Usually this relapse was quite unexpected, and it was impossible to foretell in which cases it would occur. Occasionally, however, after the tonsillitis, the rapid pulse rate failed to drop to its original level with the temperature, and this foreboded some further complication, (Cases 16, 17 and 18). The fresh rheumatic manifestations varied in each case and included arthritis, myocarditis, endocarditis, pericarditis, 
nodules, and erythematous rashes. In some the relapse was serious and either proved fatal or invalided the children for many months. Others had no renewed carditis and complained merely of a few minor pains which disappeared when the temperature subsided.

Previous to the attack of tonsillitis all the patients had been convalescent with quiescent valvular lesions and had been under continuous observation for several months, during which their general health had shown steady improvement and the temperature and pulse rate had been normal. Sixteen of the children who caught the throat infection had had their tonsils removed at some earlier date. In their case pharyngitis with tonsillar gland enlargement took the place of tonsillitis, and in eight instances rheumatic relapses followed. Table 1 gives striking evidence that children who have had their tonsils removed are less prone to epidemics of naso-pharyngeal infections than those in whom the operation has not been performed. The figures are even more significant when we find that the proportion of tonsillectomized to non-tonsillectomized children who were in the hospital during these epidemics was about the same. This diminished liability to acute throat infections, and hence to subsequent rheumatic relapses, places the tonsillectomized children in a superior position to the non-tonsillectomized. But the corollary cannot be taken further, and judging from the figures, tonsillectomy in rheumatic children can act as a two-edged sword. It does not altogether preclude acute throat infection, and. when this occurs there is more likelihood of renewed and often severe rheumatism. Relapses were observed after acute naso-pharyngeal infection in 50 per cent. of the children who had had their tonsils removed, but only in 30 per cent. of the others who had not had the operation. In both groups the severity of the relapses were strictly comparable. Only brief reference to these important points is made here ; the whole matter is more fully discussed later.

Reverting to the actual cases that were observed, one of the most curious features was the almost constant quiescent interval of 10 to 21 days between the onset of the naso-pharyngeal infection and the re-awakened symptoms of rheumatism.

Severe relapses of rheumatism did not inevitably follow the throat infection, but several, after the afebrile interval, developed a well-marked pyrexia and tachycardia unaccompanied by any other obvious manifestations of rheumatism (Cases 1, 2, 3 and 4). This was perhaps the most interesting of all the observations made. The temperature undoubtedly pointed to a reaction on the part of the body against an infection, which, considered in conjunction with the other cases, was probably rheumatic in origin and bore a direct relationship to the preceding throat infection. Presumably in these purely pyrexial cases, which recovered completely after a week without any evidence of fresh cardiac involvement, the patient's defences had been strong enough to overcome the reawakened infection and were able to arrest the development of serious rheumatism. In many others, unfortunately, the relapses were more serious and the appearance of nodules for the first time in patients under constant observation was perhaps the best evidence of the widespread return of rheumatic 
TABLE 2

Rheumatic Relapses following aCUTE NASp-PhaRYNGeal INFECTION.

\begin{tabular}{|c|c|c|c|c|c|c|}
\hline \multirow{2}{*}{$\begin{array}{c}\text { Number } \\
\text { of } \\
\text { case }\end{array}$} & \multirow{2}{*}{$\begin{array}{c}\text { Previous heart } \\
\text { lesion }\end{array}$} & \multicolumn{3}{|c|}{ Tonsils. } & \multirow{2}{*}{$\begin{array}{c}\text { Interval } \\
\text { between } \\
\text { throat in- } \\
\text { fection and } \\
\text { rheumatic } \\
\text { relapse }\end{array}$} & \multirow{2}{*}{$\begin{array}{c}\text { Nature of } \\
\text { rheumatic relapse }\end{array}$} \\
\hline & & Removed & Healthy & Septic & & \\
\hline 1 & Mitral regurgitation & + & & & 17 days & Pyrexia only. \\
\hline 2 & $\begin{array}{l}\text { Aortic regurgitation } \\
\text { Mitral endocarditis }\end{array}$ & + & & & 18, & Pyrexia only. \\
\hline 3 & Mitral stenosis & + & & $\begin{array}{l}\text { Rem- } \\
\text { nants }\end{array}$ & 21, & Pyrexia only. \\
\hline 4 & Mitral regurgitation & & + & & 22, & Pyrexia only. \\
\hline 5 & Aortic regurgitation & + & & & 10, & Pyrexia. Arthritis. \\
\hline 6 & Mitral regurgitation & & & + & 1 month & Pyrexia. Arthritis. \\
\hline 7 & Mitral stenosis & & + & & 21 days & Pericarditis. \\
\hline 8 & Mitral regurgitation & & + & & 21, & Carditis. \\
\hline 9 & Mitral regurgitation & + & & & 20, & Pericarditis. \\
\hline 10 & Mitral endocarditis & & + & & 18, & Carditis. \\
\hline 11 & Mitral regurgitation & & + & & 13, & $\begin{array}{l}\text { Pericarditis. Nodes. } \\
\text { Mitral stenosis. }\end{array}$ \\
\hline 12 & $\begin{array}{l}\text { Mitral and aortic } \\
\text { regurgitation. }\end{array}$ & & & + & 12, & Carditis. \\
\hline 13 & Mitral stenosis & & + & & 21, & $\begin{array}{cc}\text { Carditis. } & \text { Nodules. } \\
\text { Aortic } & \text { regurg. }\end{array}$ \\
\hline 14 & Mitral stenosis & + & & & 1 month & $\begin{array}{l}\text { Rheumatic fever. } \\
\text { Chorea. Nodules. } \\
\text { Aortic regurg. }\end{array}$ \\
\hline 15 & Mitral stenosis & & + & & 17 days & $\begin{array}{l}\text { Pericarditis. } \\
\text { Aortic regurg. }\end{array}$ \\
\hline 16 & Mitral stenosis & & + & & 10, & Pericarditis. \\
\hline 17 & Mitral stenosis & & + & & 12, & Pericarditis. Nodes. \\
\hline 18 & Mitral endocarditis & + & & $\begin{array}{l}\text { Rem- } \\
\text { nants }\end{array}$ & 15, & Carditis. Nodules. \\
\hline 19 & $\begin{array}{l}\text { Mitral stenosis } \\
\text { Aortic regurgitation }\end{array}$ & & + & & 17, & Pericarditis. \\
\hline
\end{tabular}


TABLE 2-continued.

\begin{tabular}{|c|c|c|c|c|c|c|}
\hline \multirow{2}{*}{$\begin{array}{c}\text { Number } \\
\text { of } \\
\text { case }\end{array}$} & \multirow{2}{*}{$\begin{array}{l}\text { Previous heart } \\
\text { lesion }\end{array}$} & \multicolumn{3}{|c|}{ Tonsils } & \multirow{2}{*}{\begin{tabular}{|c|} 
Interval \\
between \\
throat in- \\
fection and \\
rheumatic \\
relapse
\end{tabular}} & \multirow{2}{*}{$\begin{array}{l}\text { vature of } \\
\text { rheumatic relapse }\end{array}$} \\
\hline & & Removed & Healthy & Septic & & \\
\hline 20 & Mitral regurgitation & + & & & $\begin{array}{l}\text { Imme- } \\
\text { diately. }\end{array}$ & $\begin{array}{l}\text { Arthritis. } \\
\text { Pericarditis. }\end{array}$ \\
\hline 21 & Mitral regurgitation & & & + & 18 days & Pericarditis (death). \\
\hline 22 & Mitral stenosis & & & + & 12, & Pericarditis (death). \\
\hline 23 & $\begin{array}{l}\text { Mitral stenosis. } \\
\text { Aortic regurgitation }\end{array}$ & 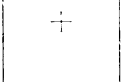 & & & 14 & Pericarditis (death). \\
\hline 24 & Mitral stenosis & & $\div$ & & 21, & Arthritis. Nodules. \\
\hline 25 & Mitral stenosis & + & & & $21 \quad$, & Carditis \\
\hline 26 & Mitral stenosis & & t & & 15, & (arditis (death). \\
\hline 27 & Mitral stenosis & + & & & $21,$, & ('arditis (death). \\
\hline
\end{tabular}

Cases 23 to 27 , from Cheyne Hospital for Children, have been added by the courtesy of Dr. Sheldon. They are not included in Table 1.

Fuller details of the whole series will be found in the Appendix.

infection throughout the body (Cases 11, 13, 14, 17, 18 and 24). One of the curious features was that the nodules did not appear at the height of the renewed rheumatic symptoms, but were only discovered one to three months later with other signs of a smouldering infection.

I have searched in vain for some indication in the age, the previous history, the severity of the cardiac lesions, or the general state of the throat, which would give some indication whether a relapse was to be expected after tonsillitis or pharyngitis in these rheumatic children. It was just as difficult to foretell how severe the relapses would be.

Study of this series of cases suggests that a preliminary infection of the throat is even more common than is usually supposed in acute rheumatism. Cases are generally brought to the doctor for advice during the acute rheumatic stage, a mild tonsillitis having previously passed unsuspected. Moreover, as often happens when the throat infection is so mild as to be symptomless, a sudden rheumatic relapse arising as long as three weeks later is unlikely to be correlated to the previous tonsillitis.

These epidemics were not localized to any particular country hospital. On studying the apparently sporadic rheumatic relapses in a similar institution, the Cheyne Hospital in London, from the special aspect of a previous throat 
infection, Dr. Sheldon discovered the same sequence of events. It transpired that this hospital, which was devoted largely to the care of children with rheumatic heart disease and had wards set aside for the purpose, had been troubled periodically with mild epidemics of tonsillitis. Severe rheumatic relapses were also liable to occur at such times, and close investigation showed that most cases were directly associated with a preceding transient throat infection (Cases 23 to 27).

In the cases both at West Wickham and Cheyne three facts are particularly worthy of note : the mild nature of the throat infection, the quiescent interval that ensues before the relapse of rheumatic fever, and in every case the freedom from active rheumatism for months beforehand. It is no exaggeration to say that acute naso-pharyngeal infection is the most serious menace to the rheumatic child with heart disease. Relapses at West Wickham unpreceded by throat infections have been exceedingly rare. During the three years that the hospital has been opened 485 children have had, on an average, six months' convalescent treatment, and only six have had serious relapses which were apparently unassociated with any preceding infection.

Bacteriology of the tonsillitis. - It has been mentioned that no one type of streptococcus or of any other micro-organism seemed to be responsible for the epidemics. During the 1927 epidemic special search was made for the streptococcus which Birkhaug ${ }^{8}$ has reported to be so frequently present in the throats of rheumatic children. With the collaboration of Dr. Hedley Wright, and carefully following Birkhaug's methods of culture and technique, five cases of acute tonsillitis were investigated, but we were unable to isolate his particular organism. It was noted that many of the streptococci discovered were hæmolytic on the blood-agar plates and that the rest, cultured on boiled blood agar, were chiefly of the viridans type commonly found in the throat. In Birkhaug's series the throat cultures were not performed at the height of an acute tonsillitis; possibly his particular streptococcus is not so much in evidence during acute inflammatory conditions.

During the later epidemics the bacteriological investigaticns were undertaken by Dr. Macdonald at the Hospital for Sick Children, Great Ormond Street. A variety of streptococci were isolated, but the hæmolytic type was not so much in evidence, the majority growing either in green colonies or forming no methæmoglobin and so appearing white. Using Holman's classification, they fell mainly into the following groups:-S. pyogenes, S. mitis, and S. salivarius. In one case an organism corresponding to the one described by Birkhaug was cultured, but none of the fæcalis type was isolated. There was no appreciable difference between throat cultures in those cases where the tonsillitis was followed by a rheumatic relapse and those which were not.

These bacteriological findings are not surprising and correspond closely to those of Nabarro and Macdonald". After culturing the tonsils enucleated from rheumatic children and those from non-rheumatic cases, they found little difference in the variety of organisms isolated from the two groups.

From the available evidence it appears that no particular streptococcus is responsible for the tonsillitis occurring in rheumatic children and capable 
in many cases of producing serious relapses. With the exception of an occasional hæmolytic strain the streptococci grown in this series differed little from those normally found in healthy throats. This conclusion does not favcur the theory that a specific streptococcus is the cause of rheumatism, but points rather to the whole group of these micro-organisms as in some way responsible.

Before attempting an explanation of the relationship of rheumatic relapses to preceding acute streptococcal faucial infections, it is interesting to compare the sequence of events in scarlet fever, a clearly defined streptococcal disease which almost invariably originates in the throat.

Scarlatinal rheumatism.-Scarlet fever is likely to produce certain symptoms and pathological changes identical with those associated with the usual forms of rheumatism. Arthritis is the most common manifestation, arising in about 4 per cent. of all cases, but carditis may follow later. Although children who have previously been rheumatic subjects ore particularly liable to a relapse of arthritis or chorea during an attack of scarlet fever, this attack may lead to the first onset of rheumatic symptoms. Moreover, in some cases, chronic endocarditis of rheumatic type arises insidiously, nct preceded by symptoms of arthritis or chorea. Whether or not the hæmolytic streptococcus found in association with scarlet fever is accepted as specific for this disease, that organism probably plays its part in the production of rheumatism, not as the 'streptococcus scarlatinæ', but in the rôle of the genus streptococcus. As a member of the whole group of streptococci it acts no doubt in the same manner as its less spectacular bacterial cousins which provoke a simple tonsillitis. At any rate it appears to obey fairly closely the same incubation rules. Through the kindness of Dr. Thomson of the North-Eastern Fever Hospital I was able to investigate this point in 19 cases of scarlatinal rheumatism, and found that in 13 arthritis with pyrexia developed after an interval of 10 to 2] days from the initial scarlatinal throat infection. There was a quiescent afebrile period in nearly all (11 out of the 13), and the fresh appearance of symptoms was totally unexpected. Five who seemed to be well on the road to recovery suddenly developed pyrexia and arthritis on the twentyfirst day, and this quiescent period was just as great a feature here as in rheumatic relapses following simple tonsillitis. Unlike those cases, however, the interval can occasionally be longer than twenty-one days. When it is shorter than 10 days the arthritis is part of the acute stage of the scarlatinal attack and appears still during the first febrile period. The actual figures will be found in the Table 3 .

These cases of acute rheumatism following scarlet fever and those preceded by simple acute pharyngitis and tonsillitis point strongly to a common factor. The course of the disease, particularly the time interval which elapses between the throat infection and the systemic invasion, is best explained on an allergic basis. Further, it will be found to resemble serum disease more closely than any other example of allergy.

Allergic factors.-With a microbic infection which is not fatal, the invading micro-organisms are attacked by certain cells of the human body and broken down. By this means the disease is overcome, but in the process the body 
may become sensitized to the disintegrated products of the bacteria and will always act in eharacteristic fashion towards a fresh invasion of the same organisms. As a result of the renewed infection bacterial products will again be liberated in the body.

There is ample opportunity in childhood for sensitization of the tissues by repeated small invasions of streptococci from the tonsils. This invasion may not at first produce any definite signs of disease beyond a possible deterioration in general health. Nevertheless a process of sensitization has supervened, and when another attack of tonsillitis occurs, manifestations of rheumatism may appear as a result of the acquired bacterial allergy.

TABLE 3

Details of a series of CaSES OF POST-SCaRlatinal Rheumatism.

\begin{tabular}{|c|c|c|c|c|c|}
\hline Name & $\begin{array}{c}\text { Age } \\
\text { in } \\
\text { years }\end{array}$ & $\begin{array}{c}\text { Previous } \\
\text { rheumatism }\end{array}$ & $\begin{array}{c}\text { Heart lesion } \\
\text { developing after S.F. }\end{array}$ & $\begin{array}{l}\text { Day of disease } \\
\text { when rheumatic } \\
\text { symptoms first } \\
\text { appeared }\end{array}$ & $\begin{array}{l}\text { Afebrile } \\
\text { period }\end{array}$ \\
\hline E.R. & 25 & Arthritis & & 4th & No \\
\hline G.K. & 22 & $\begin{array}{l}\text { Carditis. Aortic } \\
\text { regurgitaticn }\end{array}$ & & 5 th & , \\
\hline H.P. & 19 & $\mathrm{Nil}$ & & 7 th & , \\
\hline G.M. & $5 \frac{1}{2}$ & , & Mitral endocarditis & 10th & , \\
\hline V.C. & 8 & 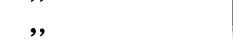 & Mitral endocarditis & 11th & 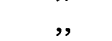 \\
\hline V.C. & 8 & , & & 12th & , \\
\hline J.F. & 11 & , & . & 14th & Yes \\
\hline $\mathrm{LS}$ & 19 & , & & 14th & , \\
\hline К.H. & 12 & $\begin{array}{l}\text { Carditis. Aortic } \\
\text { regurgitation }\end{array}$ & & 17 th & No \\
\hline S.S. & 11 & Rheumatic fever & Mitral endocarditis & 19th & Yes \\
\hline A.W. & $14 \frac{1}{2}$ & Arthritis & Mitral endocarditis & 21 st & , \\
\hline M.M. & $14 \frac{1}{2}$ & Nil & & $21 \mathrm{st}$ & , \\
\hline H.B. & 26 & $\begin{array}{l}\text { Rheumatic fever. } \\
\text { Carditis. Mitral } \\
\text { regurgitation }\end{array}$ & Mitral stenosis & $21 \mathrm{st}$ & , \\
\hline M.S. & 19 & Nil & & 21 st & , \\
\hline B.S. & 17 & Arthritis & & 21 st & , \\
\hline R.F. & $7 \frac{1}{2}$ & Nil & Mitral endocarditis & 22nd & , \\
\hline W.A. & 28 & Arthritis & & 24th & , \\
\hline C.S. & 18 & Nil & & 27 th & ,, \\
\hline L.B. & 7 & ," & & 32nd & ,. \\
\hline
\end{tabular}

The rheumatic state, as Weintraud ${ }^{10}$ pointed out, resembles serum sickners in many ways. In children marked serum sickness with tender joints is comparatively uncommon, and this may have some bearing upon the usual mild degree of arthritis seen in acute rheumatism at that age. Later, in adult life the joints appear to be a more favourite situation for allergic inflammatory reactions, so that both in the course of acute rheumatism and in serum disease quite severe arthritis is often seen. 
Objection may be raised that the onset of rheumatism may be so insidious that it is often impossible to hold any antecedent infection directly responsible. In a fair proportion, of cases, however, the first symptoms date back to a definite illness. Scarlet fever is, of course, the best known example, but the commencement of rheumatism has also been traced to other infections in which the streptococcus is much in evidence, such as measles, influenza and diphtheria. Simple throat infections occur in many more, and from the cases I h $\mathrm{zve}$ described it is apparent that the tonsillitis or pharyngitis is often so mild as to be easily overlooked.

The latent period in acute rheumatism and serum disease.-Viewed from an allergic standpoint, the streptococcus in all the provocative infections mentioned, such as scarlet fever and tonsillitis, may truly be described as the rheumatic antigen.

The time required for its action to take place is somewhat similar to that which follows the injection of horse serum in man. Thus, after a first injection of serum, symptoms do not appear for well over a week,and in children may then be quite transient. A second injection soon after the first definitely increases and speeds up the reaction, but if a considerable time is allowed to elapse between the two injections, the patient's reactions tend to revert to the original state and symptoms only appear after a longer interval.

If now in place of serum we imagine some streptoccccal infection such as tonsillitis which is followed by symptoms of rheumatism instead of serum disease, the time relationships are fairly comparable. The original throat infection, corresponding to the first injection of serum, would be followed after an interval by growing pains, often so fleeting as to pass unrecognized. A second sore throat following soon afterwards. wculd now, however, precipitate an attack of acute rheumatism, whereas if the second attack of tonsillitis occurs many months later, a longer interval takes place before rheumatic manifestations appear. I have noticed this in many cf my cases. For instance, the first attack of rheumatic fever in a child with a previous history of growing pains and an indefinite histcry cf throat infection is often immediately preceded by tonsillitis. He recovers from this and remains well for many months until at last a renewed throat infection is followed by another relipse of rheumatism. On this occasion, however, there is quite an appreciable interval between the onset of tonsillitis and the recurrence of rheumatic symptoms.

In the rheumatic relapses following tonsillitis or pharyngitis which have been described, the patient had almost invariably been free from throat infections and rheumatism for many months, and the interval was 10 to 21 days. Twenty-one days has olso been shown to be a favourite interval before rheumatism occurs after scarlet fever.

A possible interpretation of these observations is that the rheumatic patient is in a maximum hyper-sensitive state from the 10th to the 21st day after the antigenic throat infection, at any time during which a reaction in the form of an attack of rheumatism is liable to occur. In this connection it is of some interest to find that the greatest period of hyper-sensitiveness in animals after the injection of foreign protein is also from the 10th to the 21 st $\operatorname{day}^{11,12}$. 
Investigations into the type of case most liable to relapse.- It has already been stated that it was impossible to foretell in which cases a relapse would occur after an acute throat infection.

Two separate investigations were undertaken dealing with the whole quesiion, one being directed towards the reaction of the patient, and the other towards the state of the tonsils.

1. The Dick test in Rheumatic Children. One of the advances in medicine of our time has been the discovery of a means of detecting a patient's susceptibility to certain diseases by his reaction on intra-dermal injection to products of the micrc-organism concerned in the particular infection. Thus tests such as the Dick and the Schick give a fair indication whether the patient is able to resist infection by scarlatina and diphtheria respectively. Attempts have been made to bring rheumatism into line with these other infections, and skin testing with various streptococcal products has been attempted

TABLE 4

Dick tests in 234 RheUMatic ChILDREN.

\begin{tabular}{|c|c|c|c|c|}
\hline Age in years & No. tested & Positive & Negative & $\%$ positive. \\
\hline 4 & 1 & 1 & & \\
\hline 5 & 9 & 6 & 3 & 66 \\
\hline 6 & 18 & 11 & 7 & 61 \\
\hline 7 & 41 & 21 & 20 & 51 \\
\hline 8 & 31 & 18 & 13 & 58 \\
\hline 9 & 26 & 12 & 14 & 46 \\
\hline 10 & 14 & 5 & 9 & 36 \\
\hline 11 & 29 & 11 & 18 & 38 \\
\hline 12 & 26 & 9 & 17 & 34 \\
\hline 13 & 35 & 14 & 21 & 40 \\
\hline 14 & 14 & 3 & 11 & 21 \\
\hline
\end{tabular}

by Birkhaug ${ }^{13}$, Kaiser ${ }^{14}$, Swift, Derick and Hitchcock ${ }^{15}$, Howell and Corrigan ${ }^{16}$, Swift, Wilson and Todd ${ }^{17}$, and others. So far the results have been too irregular and conflicing to be of any prognostic value.

The Dick test on the other hand is quite definite and indicates whether or not the patient is susceptible to toxins of the hæmolytic Streptococcus scarlatinæ. Since this particular streptococcus is also known to provoke rheumatism, and since other hæmolytic strains were occasionally isolated from the epidemics of tonsillitis described in this paper, it seemed worth while investigating the reaction of a number of rheumatic children to Dick toxin.

In all, 234 children were tested at West Wickham and the results obtained, arranged in age groups, are shown in Table 4.

These figures compare very closely with those obtained in normal children of the same age. In the accompanying graph (Fig. 1) the percentage of positive Dick reactions amongst English (Joe $\left.{ }^{18}\right)$, German $\left(\right.$ Heller $^{19}$ ), and American children (Smith and Taylor ${ }^{20}$ ), are placed side by side with my curve in rheumatic 


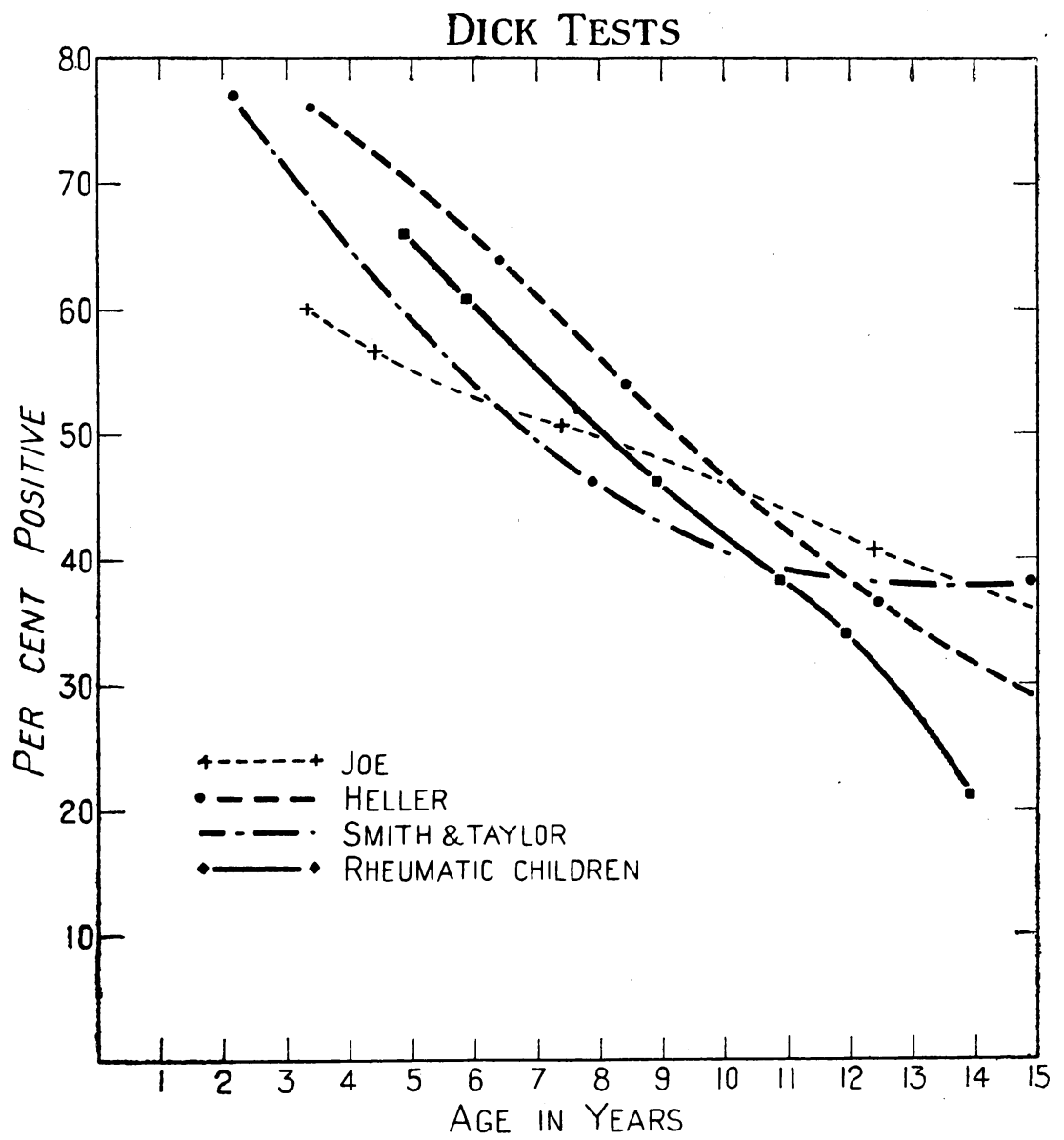

Fic. 1-Curves showing that the percentage of Jick-positive reactions according to age in rheumatic children varies little from that found in normal children.

children. They will all be found to correspond very closely, and this is strong evidence that rheumatism has little influence on the Dick reaction. Nevertheless, it was thought that children who were Dick-negative might have acquired a certain immunity to further attacks of rheumatism. Among the children who were tested, 38 caught a throat infection whilst at the hospital. Of these, 15 had a relapse of rheumatism, whilst the remaining 23 made an uneventful recovery. The following summary (Table 5) shews that relapses

TABLE :5

The Relationship of the Dick test to rheunatic relapses.

\begin{tabular}{|c|c|c|c|c|c|}
\hline & & & Total & Positive & Negative \\
\hline $\begin{array}{cc}\text { Cases with relapse } \\
\text { infections } & \ldots\end{array}$ & $\begin{array}{c}\text { after acute } \\
\ldots\end{array}$ & $\begin{array}{c}\text { naso-pharyngeal } \\
\ldots \quad \ldots \quad \ldots\end{array}$ & 15 & 7 & 8 \\
\hline $\begin{array}{c}\text { Cases without relapse } \\
\text { infections }\end{array}$ & $\begin{array}{ll}\text { after } & \text { acute } \\
\ldots & \ldots\end{array}$ & $\begin{array}{c}\text { naso-pharyngeal } \\
\ldots \quad \ldots \quad \ldots\end{array}$ & 23 & 11 & 12 \\
\hline
\end{tabular}


occurred in as many Dick-positive as Dick-negative reactors. None of the 38 children had previously had scarlet fever. The tonsils and adenoids had been removed in 7 cases before their admission to West Wickham, and the fact that five of these were Dick-negative and only two Dick-positive was regarded as a coincidence.

Thus it appears that the Dick test is of no value in foretelling whether a rheumatic patient is liable to further attacks of the disease. Nor can it be said that an acquired immunity to the scarlatinal streptococcus, as shcwn by a Dick-negative reaction, protects the patient against further rheumatism. The number of children who were Dick-negative and yet relapsed is sufficient proof.

Rheumatism is unlike scarlet fever in that one attack apparently confers no immunity against subsequent recurrences. Should a reliable streptococcal filtrate eventually be found which will give constant results on intradermal injection, we should rather expect rheumatic patients to react towards it like tuberculous subjects do towards tuberculin. Recent researches seem to point in this direction, and the most tenable view is to regard the high percentage of positive skin reactions that have been obtained in rheumatic patients with various streptococcal filtrates, not as a specific indication of rheumatism, but rather as a mark of general streptococcal hyper-sensitiveness.

2. The protective role of the tonsil in rheumatism. The second method of investigation, directed towards the state of the tonsils, led to a somewhat unexpected conclusion. The belief that areas of chronic focal sepsis in the throat are often the origin of acute rheumatism followed naturally on the repeated discovery of a high incidence of chronic throat infection in rheumatic children. This hypothesis may be true in the first instance, but as far as relapses following tonsillitis are concerned, the evidence is in direct opposition to the accepted teaching. Heretical though it may appear, the experience at the two convalescent hospitals already mentioned indicates that apart from a detrimental effect on the general health, septic tonsils are to a certain extent a safeguard against serious relapses of rheumatism. The liability of acute throat infections to provoke a relapse of rheumatism has been stressed. This was particularly noticeable in children with healthy tonsils or in those who had previously had them removed. On the other hand, in patients who obviously had chronic septic tonsils, the supervention of acute tonsillitis was not so likely to cause fresh rheumatism.

In the notes made during the physical examination of a large series of cases on admission to. West Wickham during the last three years, I have directed special attention to the condition of the tonsils. They have been presumed to be septic either when they appeared markedly enlarged and obviously infected, or in the case of small buried tonsils, when the tonsillar glands were easily palpable.

Sometimes enlarged tonsillar glands remain palpable long after the tonsils have been efficiently removed. The presence of palpable tonsillar glands after tonsillectomy has not, - therefore, been taken as an indication of active pharyngeal infection, provided the operation has been satisfactorily performed. 
The results of this enquiry are given in Table 6 and clearly establish the point I wish to emphasize, that in the event of acute tonsillitis or pharyngitis occurring, a previous long-standing throat infection is some protection against a relapse of rheumatism. Among children who had a rheumatic relapse after an acute throat infection, the large majority had either no tonsils or healthy ones, whereas in the children who did not relapse, septic tonsils were a common feature.

The probable explanation of these facts is that a perpetual streptococcal throat infection stimulates the defensive mechanism of the body so that it is fairly well prepared against any further acute attack of the same type of microorganisms. On the other hand the rheumatic patient who has either had his tonsils removed or who has not recently experienced a streptococcal throat infection is, in popular terms, off his guard when the sudden acute invasion occurs.

TABLE 6.

THE FFFECT OF HEALTHY THROATS AXI) (HRONIC SEPTIC TONSILS RESPECTIVEL ON RHEUMATIC RELAPSES FOLLOWING ACUTE INFECTION OF THE NASO-PHARYNX.

I. Acute tonsillitis or pharyngitis followed by relapse. *

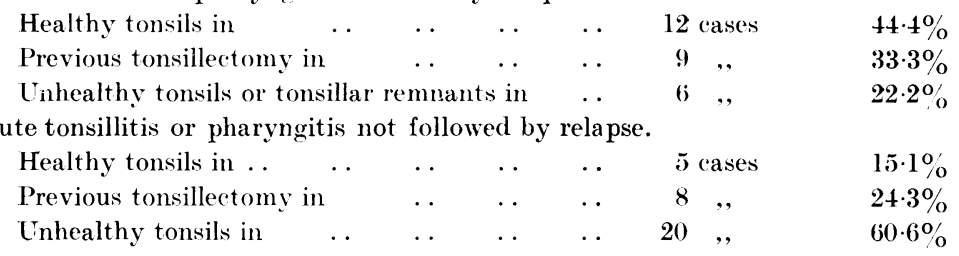

It is interesting to note that twenty-five years ago Watson Williams ${ }^{21}$ arrived at a somewhat similar conclusion. In 1904 he wrote as follows :

I came to the conclusion that when tonsillitis is associated with marked hypertrophy of the tonsils, with or without enlargement of the cervical glands, there is less tendency to the development of systematic rheumatism than in patients without these hypertrophic changes; in other words, that pronounced local inflammatory reaction is protective, while the slighter forms of tonsillitis without resulting lymphoid tissue hypertrophy are more prone to be the precursors of acute systemic infection.

The series of rheumatic relapses that have been described certainly bear out this statement, which has apparently been forgotten or discredited by most of those who have since written on the subject of rheumatism.

These are disturbing facts for those who recommend tonsillectomy as routine treatment in acute rheumatism, irrespective of the condition of the tonsils. Even when they are septic the evidence shows that the operation should not be undertaken lightly. Thus the decision must necessarily rest largely

* Two cases had had tonsillectomy incompletely performed and there were small remnants left with corresponding enlarged tonsillar glands. They were therefore included under the third category-unhealthy tonsillar tissue.

Five cases are also added from Cheyne Hospital which were under the care of Dr. Sheldon. 
on the effect of this chronic focus of infection on the general health. If the tonsils are obviously detrimental to the patient's health apart from rheumatism, their removal would seem justifiable, as in that case the effect of leaving them would be more harmful than the possible risk of a future acute throat infection and relapse.

The conclusions so far reached here in regard to tonsillectomy are mostly based on observations on a group of rheumatic children with well-established and often advanced heart lesions. The question of tonsillar operation frequently arises at this late stage of the disease so that the arguments that have been produced have a true bearing and should influence the decision. To use them as proof against the advisability of tonsillectomy in early cases of rheumatism would be stretching the evidence too far. This part of the problem is beyond the scope of the present investigation and any attempt to deal with this difficult question would be completely dwarfed by the extent of American statistical enquiries. Their conclusions are unfortunately contradictory and the reader is left in dcubt as to the prophylactic value of tonsillectomy at any stage of rheumatism. Kaiser ${ }^{22}$, for instance, produces sound reasons in favour of the operation, while Wilson, Lingg, and Croxford ${ }^{23}$ produce equal cogent evidence against it.'

The question of contagion in rheumatism.-The facts that have been brought forward in this paper have considerable bearing on the question of contagion in rheumatism, and it may be of some value to enquire how far they support the theory that acute rheumatism is an infectious disease.

Although acute rheumatism is generally regarded as a sporadic disease, there is good reason to believe that at times it may assume epidemic proportions. Longstaffe ${ }^{24}$ drew attention to this and found, moreover, that in England from 1900 to 1924 the prevalence of erysipelas, septicæmia, scarlet, puerperal and rheumatic fever occurred in synchronous waves. Atwater ${ }^{25}$ was of the same opinion, and pointed out the striking analogy of the death-rate curves of this group of infections over the same period of years. The rise and fall in the mortality of each disease coincided to a remarkable degree.

The question of contagion in acute rheumatism naturally arises from these observations. Such a hypothesis needs very careful investigation, particularly as now a widespread campaign is in progress against the disease. At present the medical world is not even agreed as to the exact nature of rheumatic infection. To declare it contagious without sufficient proof would do much harm by unnecessarily raising a scare amongst the public, and where housing resources are so often inadequate, add considerably to the difficulties of the practical management of the rheumatic patient. The experience of the London hospitals is definitely against the view, for although rheumatism is so common that it is not unusual for one-third of the patients in a children's ward to be suffering from various stages of the disease, there is no evidence whatever that the infection spreads to others who are not rheumatic.

Local epidemics have been reported from time to time which certainly were suggestive of contagion. In most instances these occurred in institutions mainly or entirely devoted to the care of convalescent rheumatic children. 
Boaz and Schwartz ${ }^{26}$ describe two such ward epidemics at the Montefiori Hospital, and Hiller and Graef ${ }^{27}$ report a similar outbreak at a convalescent home for cardiac patients. Other local epidemics of rheumatic fever have been described by Felthamp ${ }^{28}$, Hermann ${ }^{29}$, Raven ${ }^{30}$, and Grenet ${ }^{31}$.

In the epidemics of acute rheumatism which $I$ have witnessed throat infections were always present, mostly in so mild a form, however, that without a daily temperature chart the tonsillitis might easily have passed undetected. In this way a false impression might have arisen that the acute rheumatism was contagious whilst as a matter of fact it was the non-specific infection that preceded it. Actually Boaz and Schwartz's epidemic was closely associated with broncho-pneumonia, and although no bacteriological details are given, it is not unlikely that it was an infectious type. Hiller and Graef in the account of their outbreak drew attention to the prevailing catarrh of the upper respiratory tract which is notoriously infectious.

On the whole, then, there seems to be no convincing evidence that acute rheumatism is infectious, and the benefit of six months' convalescent treatment in the country for children just recovering from an acute attack of rheumatism is so marked, that it would be a retrograde step if the occasional alarming experiences as have been described in America and various European countries, led to a complete reaction against this relatively new form of insticutional treatment. On the other hand, they do emphasize the extreme care needed in the choice of a suitable site for the Home, and it seems clear that small wards and facilities for efficient isolation should be provided as the best means of preventing the possible spread of tonsilliiis.

In addition an attempt has recently been made to forestall the rheumatic relapses once the tonsillitis has occurred by a simple therapeutic measure. The method requires further trial but has been successful enough to warrant a detailed account.

The prophylactic use of aspirin.-The resemblance between serum disease and acute rheumatism has been fully discussed in an earlier section of this paper, and in support of that theory it is interesting to note that cer a in drugs which have a beneficial effect on rheumatic arthritis also have an influence on the joint manifestations in serum disease. In this connection, Derick, Hitchcock and Swift $^{32}$ found that neo-cinchophen (tolysin) or aspirin, given in adequate dosage to patients for a period of 10 to 14 days immediately following an injection of horse serum, usually prevented the onset of arthritis, although other symptoms of the serum reaction such as urticaria and lymphadenitis were uninfluenced. They showed further that the serum of patients treated in this manner contained no antibody (precipitin), and that the titre of the horseserum antigen remained at a high level for a considerable period. On the other hand, if aspirin or tolysin were withheld, subjects who had received an injection of horse serum showed a marked rise in the antibody (precipitin) content of the blood and simultaneously a drop in the antigen curve at the time of the occurrence of arthritis.

The view that an irritating compound is formed by the local union of antibody and antigen which causes an inflammatory process in the joint (Opie ${ }^{33}$ and 
others) has many points in its favour ; but exactly how drugs such as aspirin and tolysin inhibit the formation of circulating antibody is not clear. The problem is further complicated by the fact that urticaria is uninfluenced, although it is presumably also the result of an interaction between antigen and antibody.

Having in mind the possible relationship of rheumatism and serum disease, the work of these three American researchers prompted me to use aspirin as a prophylactic agent. By analogy it was thought that the acute throat infection might be held to represent the injection of serum and the rheumatic relapse which followed at least ten days later, a counterpart of the serum sickness. If this were true, aspirin given immediately after the onset of the tonsillitis might be expected to prevent or modify the rheumatic reaction. This has been the procedure in 16 cases of acute tonsillitis which occurred during the last few months. The dose of aspirin (thrice daily) has been given according to the age of the child : from 5) to 8 years, 7 grains : from 9 to 14 years, 10 grains ; and above 14 years 10 to 12 grains. The drug was started during or immediately after the tonsillitis and continued daily for a month. Contrary to former experience, no serious rheumatic relapses followed, despite the fact that both clinically and bacteriologically the tonsillitis appeared to be the same. In two cases a short bout of pyrexia followed some ten to fifteen days after tonsillitis without signs of renewed carditis. In another the temperature and pulse were normal again a week after the onset of tonsillitis, but for a few days occasional premature contractions were audible. The course of the illness in these last three cases is additional evidence that a systemic rheumatic relapse is only too ready to occur and that in all probability aspirin acts as a valuable prophylactic.

Although it is too early yet to be sure, the preceding account strongly suggests that aspirin may prevent rheumatic relapses following acute catarrhal infections. Relatively large doses are required and there appears to be little danger of toxic consequences from the quantities stated. The same amount of sodium salicylate has been tried in other cases but not with equal success. This is difficult to explain except that acetyl-salicylic acid (aspirin) is more potent than the sodium compound and, according to Hanzlik ${ }^{34}$, circulates for the most part unchanged in the body.

From what has been said it would seem wise to give a course of aspirin to every rheumatic child who catches a cold or throat infection. By this means many rheumatic relapses may possibly be averted; some will obviously still occur, since the remedy depends upon the immediate recognition of a throat infection, often a difficult matter when the rheumatic child is leading a normal life at home.

\section{Summary and conclusions.}

1. The outcome of these investigations has been to emphasize the im. portant part played by the tonsils in connection with acute rheumatism in childhood. There can be little doubt that rheumatic relapses are largely brought about by acute and often extremely mild throat infections 
2. Study of the bacteriology of the tonsillitis does not reveal any one specific type of streptococcus to be responsible either for the throat infection or for the acute rheumatism which follows.

3. The time interval of from ten to twenty-one days between the onset of tonsillitis and the rheumatic relapse is almost constant; the same interval is seen in scarlatinal rheumatism, and the whole problem is best explained on an allergic basis, comparable to serum disease. This by no means excludes a bacterial origin for rheumatic disease, since here a bacterial antigen is an essential precursor of the allergic state. Far from supplanting the streptococcus, an allergic theory helps to strengthen the view that this group of microorganisms is the exciting cause of the disease.

4. There is as yet no means of estimating a patient's power of resistance against further attacks of rheumatism. Dick testing only shows that rheumatic children behave like the rest of the normal population and,further, that rheumatic relapses occur irrespective of the reaction of the patient to this particular toxin. Skin tests with filtrates of other streptococci are also inconclusive.

5. Prophylaxis is naturally the ultimate aim, and tonsillectomy would seem to be the most obvious course. Unfortunately the operation, apart from giving some protection against epidemic sore throats, has repeatedly been shown to exert little influence in other ways in the course of rheumatism. Some evidence has been produced showing that the rheumatic patient with established heart disease is often better served by a pair of septic tonsils than by a healthy throat. The operation should therefore bè reserved for those children whose general health is being adversely affected by this chronic focus of infection.

6. Prolonged convalescence in a special country hospital has been one of the recent advances in the treatment of children with acute rheumatism and early heart disease. Epidemics of rheumatism in homes of this nature have been described, in which a preceding infection was invariably discovered. It appears that this rather than the rheumatism itself was the infectious element.

7. The problem is centred on the pharynx; it seems that if outbreaks of throat infection could be avoided, rheumatic relapses would practically never occur. To banish these infections during the winter months seems at present impossible; the most that can be done is to limit the infection by means of small wards and strict isolation.

8. Aspirin given for some weeks after the onset of tonsillitis has proved to be a valuable method of preventing the recurrence of serious rheumatism.

\section{REFERENCES.}

1. Med. Res. Council, Sp. Rep. Series, 1927, No. 114.

2. Mackie, T. T., Am. J. Med. Sc., Philad., 1926, CIXXII, 199.

3. Lambert, A., J. Am. Med. Ass., Chicago, 1920, LXXIV, 993.

4. Miller, R., Brit. Med. J., Lond., 1926, ii, Supp., 16.

5. St. Lawrence, W., J. Am. Mled. Ass., Chicago, 1920, LXXV, 1035.

6. Poynton, F. J., Brit. Med. J., Lond., 1925, ii, 788.

7. Bertram, M., Ibid., 1925, i, 496 . 
8. Birkhaug, K. E., J. Infect. Dis., Chicago, 1927, XL, 549.

9. Nabarro, D. \& Macdonald, R.A., Brit. Med. J., Lond., 1929, ii, 758.

10. Weintraud, W., Berlin klin. Wchnschr., Berlin, 1913, L, 1381.

11. Richet, C., L'Anaphylaxie, Paris, 1923, 25.

12. Kolmer, J. A., Infection, Immunity \& Biol. Therapy, Philad., 1923, 618.

13. Birkhaug, K. E., J. Infect. Dis., Chicago, 1929, XLIV, 363.

14. Kaiser, A. D., Ibid., 1928, XLII, 25.

15. Swift, H. F., Derick, C. L., \& Hitchcock, C. H., J. Am. Med. Ass., Chic., 1928, XC, 906.

16. Howell, K. M. \& Corrigan, M., J. Infect. Dis., Chic., 1928, XLII, 149.

17. Swift, H. F., Wilson, M. G., \& Todd, E. W., Am. J. Dis. Child., Chic., 1929, XXXV II, 98.

18. Joe, A., Lancet, Lond., 1925, ii, 1321.

19. Heller, S., Med. Klin., Berlin, 1927, XXIII, 320.

20. Smith, J. \& Taylor, J. S., J. Hyg., Lond., 1926, XXV, 90.

21. Watson Williams, P., Bristol Med. Chir. J., Bristol, 1904, XXII, 215.

22. Kaiser, A. D., J. Am. Med. Ass., Chic., 1927, LXXXIX, 2239.

23. Wilson, M. G., Lingg, C. \& Croxford, C., Am. Heart. J., St. Louis, 1928, IV, 197.

24. Longstaff, G. (B., Trans. Epidem. Soc. Lond., Lond., 1905, XXIV, 33.

25. Atwater, R. M., Am. J. Hyg., Baltimore, 1927, VII, 343.

26. Boaz, E. P., \& Schwartz, S. P., Am. Heart. J., St. Louis, 1927, II, 375.

27. Hiller, R. I., \& Graef, I., Ibid., 1928, III, 271.

28. Felthamp, T. E. W., Ned. Tijds. u. Geneesk., Haarlem, 1887, XXIII, 141.

29. Hermann, H., Münch. Med. Wchnschr., Münich, 1924, LXXI, 330.

30. Raven, M. O., Lancet, Lond., 1923, ii, 1227.

31. Grenet, H., Presse méd., Paris, 1915, XXIIT, 428.

32. Derick, C. L., Hitchcock, C. H., \& Swift, H. F., J. Clin. Invest., Baltimore, 1928, V, 427.

33. Opie, E. L., J. Immunol., Baltimore, 1924, IX, 231.

34. Hanzlik, P., Medicine, Baltimore, 1926, V, 197.

\section{Appendix. \\ Relapses following aCUTE NaSO-PHARYNGEAL INFeCtions.}

Case 1.-A.B., a girl aged 12 years with mitral regurgitation following two attacks of rheumatic fever, one with pericarditis three months previously. Tonsils removed at the age of three years. No cardiac enlargement or signs of rheumatic activity. Pharyngitis, followed 17 days later after quiescent interval by slight rheumatic fever lasting two weeks. Complete recovery and no further cardiac involvement.

Case 2.-G. S., a boy aged 6 years with aortic regurgitation and potential mitral stenosis following three attacks of rheumatic fever, one with pericarditis, since the age of four. No cardiac enlargement or signs of rheumatic activity. Tonsils removed before the onset of rheumatism. Pharyngitis, followed 18 days later after quiescent interval by renewed pyrexia and tachycardia. No further rheumatism or cardiac involvement.

Case 3.-M. B., a girl aged 13 years with mitral stenosis and moderate cardiac enlargement. Three previous attacks of rheumatic fever. Tonsillectomy after first attack; some tonsillar remnants left. No signs of active rheumatism on admission. Tonsillitis followed by a bout of pyrexia after a quiescent period of 21 days. No other signs of rheumatism.

Case 4.-D. E., a boy aged 7 years with a history of growing pains. Tonsils healthy. Mitral regurgitation; no cardiac enlargement and no signs of activity. Tonsillitis, followed by bout of pyrexia 22 days later with quiescent period intervening. No renewed manifestation of rheumatism.

Case 5.-E. G., a girl aged 14 years. Rheumatic fever with pericarditis five years previously, and since then periodic attacks of arthritis and chorea. Aortic regurgitation with moderate 
cardiac enlargement. Tonsillectomy after first onset of rheumatism. Acute pharyngitis, followed 10 days later by renewed temperature with arthritis. No further cardiac involvement.

Case 6. - O. T., a girl aged $7 \frac{1}{2}$ years with mitral regurgitation and moderate cardiac enlargement following rheumatic fever nine months previously. Septic tonsils. No signs of rheumatic activity until acute tonsillitis caused return of rheumatic fever and pain after a month's interval. No further cardiac involvement.

Case 7.-P. S., a girl aged 10 years with cardiac involvement after rheumatic fever five years previously. Tonsils healthy. Mitral stenosis with marked cardiac enlargement. Under eontinuous observation for six months, during which time no signs of activity and no pyrexia were noticed. Tonsillitis then occurred, and 21 days later after a quiescent interval a relapse of rheumatism set in. Pyrexia and further cardiac involvement with slight pericarditis, from which the child gradually recovered in two or three months.

Case 8.-M. S., a girl aged 7 years with mitral regurgitation and slight cardiac enlargement following chorea and subacute rheumatism. Tonsils healthy. Slight pyrexia and persistent choreic movements. Normal pulse rate. Acute tonsillitis, followed 21 days later after quiescent interval by short burst of temperature and tachycardia with evidence of carditis.

Case 9.-O. C., a girl aged 8 years with mitral regurgitation following rheumatic fever one year previously. Tonsillectomy at the age of 4 years. No cardiac enlargement and no signs of activity of the disease whilst under continuous observation for two months. Acute pharyngitis then occurred, which was followed 20 days later by a rheumatic relapse with acute dilatation of the heart and pericarditis. Complete recovery from this attack in two months, and heart returned to original normal size.

Case 10.-M. C., a boy aged 6 years with mitral stenosis and moderate cardiac enlargement, following two attacks of rheumatic fever during the last two years. Tonsils not obviously diseased, but subject to frequent tonsillitis, one of which produced relapse of rheumatic fever and carditis after an interval of 18 days. Recovery after many months.

Case 11.-P. C., a girl aged 12 years with mitral regurgitation following rheumatic fever eight months previously. No cardiac enlargement and no signs of active rheumatism for at least six months. Tonsils healthy. Acute tonsillitis, followed 13 days later after quiescent period by severe rheumatic fever with acute carditis and pericarditis. Nodules developed and recovery only took place after seven months, leaving the child with mitral stenosis, aortic regurgitation and an enlarged heart.

Case 12.-D. F., a girl aged $10 \frac{1}{2}$ years with mitral and aortic regurgitation following rheumatic fever five years previously. Moderate cardiac enlargement. Septic tonsils. Acute tonsillitis, followed 12 days later after quiescent interval by rheumatic fever and acute carditis. Complete recovery from this attack after many months.

Case 13. - N. M., a girl aged 9 years, with mitral stenosis and moderate cardiac enlargement following chorea. Healthy tonsils. No signs of activity of the disease whilst under continuous observation for six months. Tonsillitis then occurred, followed 21 days later by rheumatic fever with great cardiac irregularity (auricular extra-systoles) for about a week. Nodules appeared about three months later and aortic regurgitation developed.

Case 14.-H. H., a girl aged 11 years with mitral stenosis after four attacks of chorea and pains in the limbs. Tonsillectomy after last attack. Marked cardiac enlargement and slight evidence of mild chorea; temperature and pulse, however, normal. Pharyngitis, followed a month later by renewed pyrexia. After this had subsided chorea gradually increased, aortic regurgitation developed, and nodules eventually appeared after two months.

Case 15.-J. M., a girl aged 10 years with mitral stenosis following chorea. Small healthy tonsils. Heart moderately enlarged; no signs of activity of the disease; normal pulse and temperature during six months continuous observation. Tonsillitis then occurred, and after a quiescent interval, 17 days later severe relapse of rheumatic fever with pericarditis and grave myocarditis developed, producing gradual cardiac failure. Aortic regurgitation appeared at the same time.

Case 16.-N. J., a girl aged 11 years with mitral stenosis following chorea and subacute rheumatism five years previously; repeated attacks of chorea since. No cardiac enlargement. Healthy tonsils, normal temperature and pulse rate, and no signs of active rheumatism. 
Sudden acute tonillitis, followed 10 days later by acute pericarditis and dilatation of the heart.? Temperature dropped to normal for a few days after tonsillitis but tachycardia persisted.

Case 17.-M. S., a girl aged 10 years with mitral stenosis. Rheumatic fever and pericarditis three years previously. Marked cardiac enlargement, but no signs of active rheumatism; pulse and temperature normal. Healthy tonsils. Mild tonsillitis, followed 12 days later by onset of renewed rheumatic fever with pericarditis and cardiac failure. Intervening period of normal temperature but tachycardia persisted. Erythematous rash and nodules appeared during relapse.

Case 18.-K. C., a girl aged 12 years with mitral stenosis and marked cardiac enlargement following two attacks of rheumatic fever during the last year. Tonsils removed four years previously; some remnants left. No evidence of rheumatic activity until acute pharyngitis produced relapse with carditis and nodules. Tachycardia persisted throughout, but short intervening period of normal temperature before pyrexia recurred 15 days from onset of pharyngitis.

Case 19.-D. F., a boy aged 8 years, with mitral stenosis and aortic regurgitation. No history of rheumatism, but scarlet fever two years previously. No cardiac enlargement. Small healthy looking tonsils. 'Temperature and pulse rate normal. No signs of active carditis until 17 days after very mild attack of tonsillitis, when a grave relapse of rheumatic fever with pericarditis occurred. Intervening quiescent period between tonsillitis and rheumatic relapse, during which temperature and pulse rate were normal. Gradual recovery, but child became a cardiao cripple.

Case 20.-A. R., a boy aged $6 \frac{1}{2}$ years with mitral regurgitation following rheumatic fever two years previously. Moderate cardiac enlargement. Tonsillectomy at the age of 5 years. No signs of rheumatic activity whilst under observation for two months. Acute pharyngitis followed almost immediately by severe pericarditis and arthritis.

Case 21.-D. C., a girl aged $4 \frac{1}{2}$ years with mitral regurgitation following chorea and subacute rheumatism six months previously. Slight cardiac enlargement. Unhealthy tonsils. No signs of active rheumatism. Acute tonsillitis; quiescent interval, followed 18 days later by acute pericarditis which proved fatal.

Case 22.-G. M., a girl aged 13 years with mitral stenosis and cardiac enlargement following two attacks of rheumatic fever, two and four years previously. Tonsils unhealthy. No signs of activity whilst under two months' continuous observation; normal temperature and pulse rate. Acute tonsillitis, followed 12 days later after quiescent period by fatal pericarditis.

Case 23.-L. L. aged 12 years. Rheumatic fever three years previously leading to mitral stenosis and aortic regurgitation. Tonsils were removed soon after the onset of the disease. No signs of activity during eight months' continuous observation in hospital : normal temperature and pulse rate. Pharyngitis, followed after quiescent period of 14 days by fatal pericarditis.

Case 24.-L. S., aged 12 years. Mitral stenosis. Under continuous observation in hospital for nine months during which the rheumatic condition was quiescent. Tonsils healthy. Tonsillitis, followed 21 days later by return of rheumatic pains, and nodules appeared after another four weeks.

Case 25.-F. R. Mitral stenosis. Afebrile and no signs of activity whilst under five months' continuous observation in hospital. Tonsils removed just before admission. Sudden pyrexia for one day (? pharyngitis), followed after quiescent period of 21 days by rheumatic relapse of acute carditis. Gradual recovery.

Case 26. - A. B. Aged 6 years. Mitral stenosis. Small healthy tonsils. No signs of rheumatic activity whilst under five months' continuous observation in hospital. Tonsillitis, followed 15 days later by fatal carditis.

Case 27.-E. M. History of severe recurrent attacks of rheumatism. Mitral stenosis. Tonsillectomy before admission. Gradual improvement for four months. Pharyngitis, followed 21 days later by relapse of carditis. Death from cardiac failure.

Cases 22 to 27 from the Cheyne Hospital for Children are included through the courtesy of Dr. Sheldon. 